\title{
MITIGASI KEBENCANAAN PADA SITUS MASJID RAYA SULTAN RIAU DALAM PELESTARIANNYA
}

\author{
Disaster Mitigation of Masjid Raya Sultan Riau Site and Its Conservation
}

\author{
${ }^{1}$ Theodorus A. B. N. S. Kusuma dan ${ }^{2}$ Andry Hikari Damai
}

\author{
CV Vajra Amarta Reksa \\ Jalan Pulau Nias No. 13, Denpasar, Bali \\ E-mail: theodorusbrian@gmail.com
}

\begin{abstract}
Disasters can threaten archaeological remains in Indonesia such as the Masjid Raya Sultan Riau on Penyengat Island, Tanjungpinang City, Riau Archipelago Province. This island is used as tourism destinations with a religious tourism concept, but currently, there is no maximum disaster mitigation to maintain the safety of the cultural heritage building of the Masjid Raya Sultan Riau. This research method uses a qualitative descriptive approach through existing literature and journals as well as data collection techniques for field observations of the Masjid Raya Sultan Riau. The data analysis techniques used were qualitative analysis and SWOT analysis. The SWOT analysis produced several important points as a mitigation effort, namely building a wave barrier around Penyengat Island, providing fire extinguishers, and zoning. The zoning of the cultural heritage of the Masjid Raya Sultan Riau is still integrated with other cultural heritage sites on Penyengat Island so that the Masjid Raya Sultan Riau needs to develop disaster mitigation, especially for the preservation of cultural heritage, the environment, and the tourism industry.
\end{abstract}

Keywords: cultural herigate, disaster mitigation, Masjid Raya Sultan Riau, Penyengat Island

\begin{abstract}
Abstrak
Bencana alam dapat mengancam tinggalan arkeologis di Indonesia seperti Masjid Raya Sultan Riau di Pulau Penyengat, Kota Tanjungpinang, Provinsi Kepulauan Riau. Pulau ini dijadikan salah satu destinasi pariwisata dengan konsep wisata religi, namun saat ini belum ada mitigasi bencana yang maksimal untuk menjaga keselamatan bangunan cagar budaya Masjid Raya Sultan Riau. Metode penelitian menggunakan pendekatan deskriptif kualitatif melalui literatur dan jurnal yang ada serta teknik pengumpulan data observasi lapangan Masjid Raya Sultan Riau. Teknik analisis data yang digunakan, yaitu analisis kualitatif dan analisis SWOT. Analisis SWOT menghasilkan beberapa poin penting sebagai upaya mitigasi, yaitu membangun bangunan atau struktur pengamanan di sekitar Pulau Penyengat seperti membangun bangunan penahan ombak, penyediaan pemadam api, serta zonasi. Zonasi pada cagar budaya Masjid Raya Sultan Riau masih tergabung dengan cagar budaya lainnya di Pulau Penyengat sehingga Masjid Raya Sultan Riau perlu melakukan pengembangan mitigasi bencana terutama untuk pelestarian warisan budaya, lingkungan, dan industri pariwisata.
\end{abstract}

Kata kunci: cagar budaya, Masjid Raya Sultan Riau, mitigasi bencana, Pulau Penyengat

\section{PENDAHULUAN}

Indonesia berada pada wilayah rawan terhadap bencana alam. Secara geografis, Indonesia terletak di atas sabuk api (ring of fire) dan berada pada pertemuan dua lempeng. Bencana alam berupa gempa bumi, tsunami, letusan gunung api, hingga 
gelombang pasang berpotensi merusak bangunan cagar budaya yang memiliki nilainilai penting, sehingga membutuhkan mitigasi bencana untuk meminimalisasikan kerusakan. Salah satu pulau yang memiliki cagar budaya yang penting, yaitu Pulau Penyengat.

Pulau Penyengat terletak di Kota Tanjungpinang, Provinsi Riau. Pulau ini memiliki luas $3,5 \mathrm{~km}^{2}$ dan memiliki 16 situs tinggalan arkeologis yang memiliki potensi sebagai sebuah zona wisata budaya dan sejarah. Situs tersebut yaitu, Masjid Raya Sultan Riau, Kompleks Makam Engku Puteri Raja Hamidah, Makam Raja Ali Haji, Gedung Engku Haji Daud, Kompleks Makam Raja Haji Fisabilillah, Kompleks Makam Raja Ja'Far, Kompleks Tengku Bilik, Makam Embung Fatimah, Bekas Gedung Raja Haji Abdullah (Hakim Mahkamah Syariah), Bekas Istana Raja Ali Marhum Kantor, Makam Raja Abdurrahman, Benteng Pertahanan Bukit Kursi, Perigi Puteri atau Perigi Kunci, Taman Monumen Perjuangan Raja Haji Fisabilillah, Bekas Gedung Rusydiah Klub dan Percetakan, Kompleks Makam Daeng Marewah, dan Kompleks Makam Daeng Celak. Masjid Raya Sultan Riau yang merupakan salah satu peninggalan arkeologis yang sangat bernilai penting.

Masjid Raya Sultan Riau merupakan salah satu bangunan cagar budaya yang terletak di Pulau Penyengat, Kelurahan Penyengat, Kecamatan Tanjunginang, Provinsi Kepulauan Riau. Masjid ini dijadikan bangun cagar budaya sejak tahun 2003 yang telah ditetapkan melalui Surat Keputusan Menteri Kebudayaan dan Pariwisata Nomor KM.9/PW.007/MKPO3. Masjid ini berada pada 500 meter dari bibir pantai. Kondisi ini menjadikan Masjid Raya Sultan Riau berada dalam zona yang cukup rawan dengan kebencanaan berupa gelombang pasang air laut dan kebakaran. Penting sebagai dasar mitigasi kebencanaan dalam tinggalan arkeologi diperlukan adanya upaya-upaya preventif sebagai langkah awal (Zulfiar dkk., 2014).

Pulau Penyengat merupakan mahar dari pernikahan Engku Puteri Raja Hamidah dengan Sultan Mahmudsyah pada tahun 1803 yang dikenal juga dengan nama Pulau Penyengat Indra Sakt. Pulau kecil ini merupakan tempat kedudukan para Raja RiauLingga yang mengakibatkan kental dengan budaya Melayu dan Islam, seperti Raja Ali Haji, Raja Haji Fisabilillah, Yang Dipertuan Muda Raja VII, Raja Abdurrahman, dan lainnya. Bahkan pada abad ke-19 Pulau Penyengat dijadikan pusat perkembangan kebudayaan dan kesusasteraan Melayu dan juga Islam dengan adanya Kitab Suci AlQur'an yang ditulis tangan oleh Abdurrahman Stambul.

Dibangunnya Masjid Raya Sultan Riau adalah salah satu bukti sejarah dari beberapa peninggalan Kerajaan Riau bahwa Pulau Penyengat merupakan pusat perkembangan agama Islam. Masjid ini memiliki 13 kubah dan 4 menara masjid berujung runcing setinggi 19 meter. Jumlah kubah dan menara yaitu 17 yang memiliki makna sebagai petunjuk bilangan rakaat salat dalam satu hari (Gambar 1) (Trisoko 2015). 


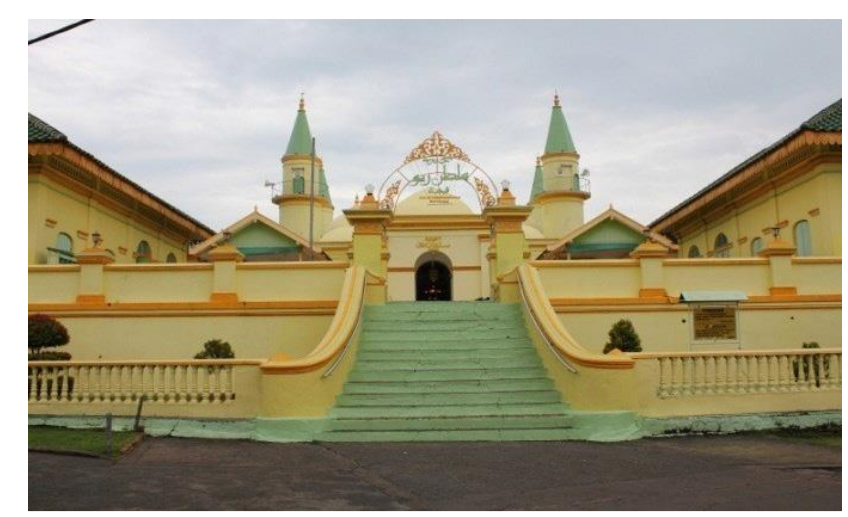

Gambar 1. Masjid Raya Sultan Riau, Pulau Penyengat (Sumber: Ramelan dkk., 2017).

Masjid Raya Sultan Riau dibangun pada masa pemerintahan Yang Dipertuan Muda Raja VII pada tahun 1832. Pada awalnya Masjid Raya Sultan Riau merupakan menara yang tingginya kurang dari 6 meter dan hanya berlantai bata. Yang Dipertuan Muda Raja VII, memperbaiki dan mempebesar secara gotong royong dengan masyarakat Pulau Penyengat. Gotong royong ini juga dibantu oleh masyarakat kawasan RiauLingga untuk membantu kesediaan bahan bangunan, seperti putih telur, tanah liat, dan kapur untuk dinding Masjid Raya Sultan Riau. Telur-telur untuk membangun masjid ini didatangkan pula dari masyarakat dan para pedagang karena Pulau Penyengat menjadi salah satu jalur perdagangan (Olisstiowati dkk., 2019).

Kawasan Pulau Penyengat dijadikan salah satu destinasi pariwisata dengan konsep wisata religi, namun saat ini belum ada mitigasi bencana yang maksimal untuk menjaga keselamatan bangunan cagar budaya. Cagar budaya dianggap memiliki banyak nilai penting sesuai dengan UU Cagar Budaya No. 11 Tahun 2010 sehingga diperlukannya mitigasi bencana pada bangunan cagar budaya ditujukan untuk mencegah kerusakan. Mitigasi bencana pada cagar budaya bertujuan untuk mengurangi dampak negatif yang ditimbulkan pada bangunan cagar budaya serta meningkatkan pengetahuan masyarakat setempat dalam menghadapi bencana, mengurangi dampak negatif dari bencana, sehingga cagar budaya tetap aman dan lestari (Chandra 2018).

Metode penelitian pendekatan deskriptif kualitatif yaitu menjelaskan permasalahan pada objek yang diteliti. Melalui literatur dan jurnal yang ada, penelitian ini dapat dikerjakan sesuai dengan kebutuhan dari permasalahan yang ada. Teknik pengumpulan data observasi lapangan dengan analisis mitigasi bencana di Pulau Penyengat terutama pada Masjid Raya Sultan Riau. Teknik analisis data yang digunakan yaitu analisis kualitatif, yaitu analisis yang menguraikan, menggambarkan, dan menjelaskan mengenai potensi dan strategi pengelolaan mitigasi bencana pada cagar budaya secara sistematis serta teknik analisis SWOT yaitu Strenghts (Kekuatan), Weaknesses (Kelemahan), Opportunities (Kesempatan), dan Threats (Ancaman). Analisis SWOT sebagai pengelolaan mitigasi bencana Masjid Raya Sultan Riau dapat disusun sebagai berikut: 
1. Strategi SO, yaitu menciptakan strategi yang menggunakan strengths (S) untuk memanfaatkan opportunities $(\mathrm{O})$.

2. Strategi WO, yaitu menciptakan strategi yang meminimalkan weaknesses (W) untuk mendapatkan opportunities $(\mathrm{O})$.

3. Strategi ST, yaitu menciptakan strategi yang menggunakan strengths (S) untuk mengatasi threats $(\mathrm{T})$.

4. Strategi WT, yaitu menciptakan strategi yang meminimalkan weaknesses (W) untuk menghindari threats (T) (Rangkuti 2011).

Data tersebut digunakan untuk menjelaskan mengenai pengelolaan mitigasi bencana pada cagar budaya.

Beberapa pustaka yang dipakai sebagai rujukan analisis yaitu Muhammad Firdaus, Yales Veva Jaya, dan Dony Apdillah (Firdaus, Jaya, dan Apdillah 2013) bahwa wilayah Kota Tanjungpinang terutama Pulau Penyengat memiliki panjang garis pantai 12.259 meter yang rawan terhadap bencana gelombang tinggi musim. Penelitian ini dilakukan dengan menggunakan aplikasi SIG memberi simpulan bahwa terdapat kerawanan untuk bencana sedimentasi kelas rawan di Kota Tanjungpinang. Artikel ini berfungsi dalam konteks membantu menganalisis bencana alam yang berpeluang terjadi di Pulau Penyengat, sehingga perlu dilakukan mitigasi bencana.

Hendro Pratikno, Hayatul Khairul Rahmat, Siswo Hadi Sumantri mengenai konsep cultural resource management dalam arkeologi yang berkaitan dengan pelestarian, pemanfaatan, dan pengembangan suatu cagar budaya serta proses mitigasi yang diawali dengan langkah-langkah konkrit. Artikel ini berfungsi dalam konteks membantu dalam merancang pengelolaan sumber daya arkeologi di Pulau Penyengat yang terintegrasi dan memiliki mitigasi bencana (Pratikno, Rahmat, dan Sumantri 2020).

Wiwin Djuwita Sudjana Ramelan, Osrifoel Oesman, Gatot Ghautama, Supratikno Rahardjo, dan Prio Widiono menjelaskan sebagian besar bangunan dan struktur cagar budaya di Pulau Penyengat dalam keadaan kosong dan tidak terurus. Artikel ini memberikan konsep zonasi pada Pulau Penyengat yaitu terdapat dua sistem blok dan sel yang digabungkan atau disebut dengan sistem gabungan yang terdiri atas zona inti, zona penyangga, dan zona pengembang dan/atau zona pendukung. Setiap penentuan zonasi berbeda dan disesuaikan dengan fungsi setiap situs. Artikel ini berfungsi dalam konteks membantu menganalisis zonasi pada Masjid Raya Sultan Riau untuk keberlanjutan sebuah situs. Zonasi akan mendukung mitigasi bencana pada situs Masjid Raya Sultan Riau di mana sistem zonasi dapat memberikan batasan untuk pengunjung yang hendak melakukan perjalanan wisata dan kegiatan lainnya (Ramelan et al., 2015).

\section{PEMBAHASAN}

Bencana merupakan peristiwa yang terjadi oleh faktor alam dan non-alam yang mengancam, mengganggu, hingga merusak kehidupan manusia. Dampak jika terjadi bencana dapat berupa korban jiwa manusia, kerusakan lingkungan, kerugian harta beda, psikologis, dan cagar budaya (Chandra 2018). Dampak yang diakibatkan dari bencana 
tersebut mengakibatkan cagar budaya akan rusak, hilang, atau musnah. Cagar budaya merupakan identitas budaya dari masyarakat yang memiliki suatu ikatan khusus. Untuk meminimalisasikan dampak negatif dari bencana perlu dilakukan mitigasi.

Cagar budaya sebagai identitas masyarakat memiliki ikatan dengan masyarakat, sehingga penting untuk dikelola dan dilestarikan. Pola mitigasi kebencanaan merupakan salah satu upaya pelestarian yang bertujuan untuk mengurangi dampak yang ditimbulkan dari bencana khususnya dampak pada cagar budaya, sebagai landasan (pedoman) untuk perlindungan, pengembangan dan pemanfaatan cagar budaya, meningkatkan pengetahuan masyarakat dalam menghadapi serta mengurangi dampak/risiko bencana sehingga cagar budaya dapat aman dan tetap lestari. Dalam mitigasi bencana, identifikasi bencana perlu dilakukan sebagai upaya preventif dalam menanggulangi bencana atau upaya untuk menghilangkan dan/atau meminimalkan ancaman bencana. Selain itu, identifikasi bencana merupakan bagian dari kesiapsiagaan bencana yang bertujuan untuk mengantisipasi bencana melalui pengorganisasian serta melalui langkah yang tepat guna dan berdaya guna (Chandra 2018).

\section{Analisis SWOT dan Nilai Penting Masjid Raya Sultan Riau}

Dalam keilmuan arkeologi, sebelum menentukkan langkah-langkah konkrit dalam mitigasi maka dilakukan telaah nilai penting suatu tinggalan arkeologi. Nilai penting arkeologi dibagi atas beberapa variabel yang terdiri dari kelangkaan, keunikan, usia tinggalan arkeologis, tataran atau kebermanfaatan, integritas, dan keaslian tinggalan (Tanudirjo 2004). Masjid Raya Sultan Riau memiliki nilai penting yang tidak dapat dikesampingkan. Salah satu nilai penting itu adalah nilai fungsional. Nilai penting tersebut merupakan hal utama dan mendasar yang mengakar kuat dalam budaya religius masyarakat sekaligus menjadi penanda sejarah panjang kesultanan Riau-Lingga. Sebagai nilai fungsional dapat dikategorikan sebagai berikut:

1. Rumah Ibadah

Masjid merupakan sebuah rumah ibadah yang digunakan oleh umat Muslim dalam menunaikan kewajibannya kepada Tuhan Yang Mahakuasa. Masjid Raya Sultan Riau digunakan oleh banyak pembesar kerajaan sekaligus Sultan Riau-Lingga dalam menjalankan ibadahnya.

2. Pendidikan Keagamaan

Pada masa Kesultanan Riau-Lingga, masjid ini digunakan sebagai tempat pendidikan agama bagi siapapun yang hendak mempelajari tentang Agama Islam. Daya tarik ilmu keagamaan dan juga tempat belajarnya para alim ulama kesultanan Riau-Lingga seperti Haji Abdul Wahab, Syeikh Ahmad Jabarati, Syeikh Muhammad Arsyad Banjar dan Syeikh Ismail.

3. Tempat Penobatan Sultan

Pada masa lampau, terdapat seseorang bergelar Engku Putri Raja Hamidah yang merupakan pemegang pusaka kerajaan sekaligus pengantin Sultan Mahmud Syah III 
sehingga keberadaan tokoh penting Pulau Penyengat tersebut mengindikasikan bahwa masjid ini memiliki keterikatan kuat dengan kesultanan Riau-Lingga (Junus 2002).

Berdasarkan pada nilai penting yang ada, maka dengan menggunakan analisis SWOT akan didapatkan hasil, yaitu (Tabel1\&2):

- Strengths atau kekuatan yang memberikan daya tarik pada sebuah tempat. Pada Kesultanan Riau-Lingga terletak pada bentuk fisik bangunan yang unik dan fungsi dari bangunan itu sendiri yang menjadi tempat pendidikan berbasis agama. Memiliki potensi wisata bahari karena langsung berhadapan dengan laut. Sudah dikenal secara luas terutama oleh rumpun Melayu.

- Weaknesses atau kelemahan dari mitigasi bencana Pulau Penyengat, yaitu kurangnya sarana prasarana pendukung mitigasi kebencanaan. Sarana prasarana yang dimaksud seperti tidak adanya keberadaan pipa air (hydrant), kurangnya papan petunjuk bencana dan papan petunjuk jalur evakuasi. Kurangnya pusat informasi wisata dari pemerintah. Masih kurangnya sarana prasarana pendukung seperti tempat sampah, sistem drainase, dan juga money changer bagi wisatawan mancanegara. Kurangnya toilet menjadi salah satu hal yang sangat krusial dalam sebuah destinasi wisata.

- Oppotunities atau peluang dari mitigasi bencana Pulau Penyengat yaitu Membuat skema mitigasi kebencanaan yang terintegrasi dengan membuat sistem zonasi yang didasarkan pada kondisi di lapangan dengan mengacu pada UndangUndang Republik Indonesia Nomor 11 Tahun 2010 tentang Cagar Budaya. Peluang ini dapat dikerjakan oleh instansi arkeologi setempat dalam hal ini BPCB Sumatra Barat. Selain itu juga dapat menambahkan papan informasi kebencanaan dan juga papan petunjuk jalur evakuasi. Penambahan aksesbilitas juga menjadi salah satu peluang yang mampu dilakukan oleh instansi terkait seperti Dinas Pekerja Umum.

- Threats atau ancaman dari mitigasi bencana Pulau Penyengat, yaitu bencana pasang air laut dan ancaman potensi kebakaran hutan dan lahan. Hal ini pernah dipublikasikan dalam rangka sosialisasi resiko bencana kebakaran hutan dan lahan oleh Polres Tanjungpinang.

Tabel 1. Analisis SWOT

\begin{tabular}{lllll}
\hline No. & Strengths & Weaknesses & Opportunities & Threats \\
\hline 1. & Terdapat 16 & Kurangnya & Membangun informasi & Berada dekat laut \\
& $\begin{array}{l}\text { cagar budaya } \\
\text { peninggalan }\end{array}$ & sarana dan & mitigasi bencana seperti & menyebabkan banjir air \\
Kesultanan & pendukung. & pengadaan papan informasi & pasang laut. \\
Riau-Lingga & & & \\
\hline
\end{tabular}




\begin{tabular}{|c|c|c|c|c|}
\hline 2. & $\begin{array}{l}\text { Destinasi } \\
\text { wisata religi } \\
\text { dan wisata } \\
\text { bahari. }\end{array}$ & $\begin{array}{l}\text { Belum } \\
\text { terdapat } \\
\text { petunjuk } \\
\text { informasi } \\
\text { mitigasi } \\
\text { bencana. }\end{array}$ & $\begin{array}{l}\text { Pembangunan sarana dan } \\
\text { prasarana pendukung yang } \\
\text { mampu menjadi tambahan } \\
\text { daya tarik wisata seperti } \\
\text { wahana olahraga air, pusat } \\
\text { infromasi wisata, money } \\
\text { changer. }\end{array}$ & $\begin{array}{l}\text { Pembagian wilayah zonasi } \\
\text { yang belum maksimal } \\
\text { menjadikan ketidakjelasan } \\
\text { dalam penentuan deliniasi } \\
\text { kawasan situs Kesulltanan } \\
\text { Riau-Lingga. }\end{array}$ \\
\hline 3. & $\begin{array}{l}\text { Dikenal secara } \\
\text { luas oleh } \\
\text { rumpun } \\
\text { bangsa } \\
\text { Melayu di } \\
\text { Pulau Sumatra }\end{array}$ & $\begin{array}{l}\text { Tidak adanya } \\
\text { sistem } \\
\text { drainase, } \\
\text { hidran air, } \\
\text { money } \\
\text { changer dan } \\
\text { juga pusat } \\
\text { informasi dari } \\
\text { pemerintah. }\end{array}$ & $\begin{array}{lrr}\text { Pembuatan zonasi } & \text { bagi } \\
\text { kawasan Kesultanan } & \text { Riau } \\
\text { Lingga yang diintegrasikan } \\
\text { dengan zonasi } & \text { Pulau } \\
\text { Penyengat dalam hal ini } \\
\text { mengacu pada } & \text { BPCB } \\
\text { Sumatra Barat. } & \end{array}$ & $\begin{array}{l}\text { Ancaman kebakaran yang } \\
\text { bisa saja terjadi akibat } \\
\text { tidak ada pengelolaan } \\
\text { kabel listrik yang baik. }\end{array}$ \\
\hline
\end{tabular}

Sumber: Analisis penulis

Strategi SO (strengths-opportunities) dapat dilakukan dengan mengkoordinasikan segala pihak yang berkepentingan untuk saling bahu-membahu dalam upaya mendorong dan memaksimalkan potensi Masjid Raya Sultan Riau. Penjaringan peluang pengembangan dapat dilakukan melaui rapat terpumpun atau Focused Group Discussion (FGD), seminar, diskusi internal terbatas, wawancara tokoh setempat, masyarakat, dan pemangku kebijakan terkait, dan lain sebagainya.

Strategi WO (weaknesses-opportunities) dapat digunakan sebagai bahan evaluasi dalam pengembangan berdasarkan pada zonasi yang ada. Pada zonasi, diperlukan pembagian deliniasi serta penentuan skala prioritas penyelamatan cagar budaya. Dalam mitigasi kepada masyarakat, perlu memperbanyak tanda-tanda peringatan di beberapa titik rawan yang berpotensi terjadinya bencana.

Strategi ST (strengths-threats) merupakan hal yang harus dicapai yang dilandaskan pada nilai penting dan rasa memiliki dari masyarakat. Perlu adanya komunikasi antara pemangku kepentingan seperti LSM atau komunitas pecinta budaya yang bekerja sama dengan masyarakat untuk melakukan sosialisasi melalui pendekatan partisipatoris. Pengembangan wisata bahari yang dilakukan dengan kesadaran akan potensi ancaman dari laut.

Strategi WT (weaknesses-threats) dapat menjadi sebuah awal yang baik dalam penentuan mitigasi kebencanaan dan memetakan segala bentuk potensi kebencanaan yang akan mengancam keberlangsungan Masjid Raya Sultan Riau. Pelaksanaan simulasi siaga kebencanaan akibat potensi bencana dari laut dalam melakukan penyelamatan cagar budaya yang melibatkan BNPB, TNI, Polri, dan BPCB Sumatra Barat. Dalam hal ini analisis SWOT yang telah dilakukan dapat dijadikan sebagai bahan pertimbangan dalam proses penentuan langkah-langkah mitigasi Masjid Raya Sultan Riau. 
Tabel 2. Analisis SWOT

\begin{tabular}{|c|c|c|c|c|}
\hline No. & $\begin{array}{l}\text { Strenghts- } \\
\text { Opportunities }\end{array}$ & $\begin{array}{l}\text { Weaknesses- } \\
\text { Opportunities }\end{array}$ & Srenghts-Threats & Weaknesses-Threats \\
\hline 1. & $\begin{array}{l}\text { Pembuatan } \\
\text { rencana studi } \\
\text { kelayakan } \\
\text { bagi } \\
\text { keberadaan } \\
\text { situs tinggalan } \\
\text { arkeologi } \\
\text { beserta } \\
\text { pendukungnya }\end{array}$ & $\begin{array}{l}\text { Bahan evaluasi } \\
\text { pengemba-ngan } \\
\text { zonasi. }\end{array}$ & $\begin{array}{l}\text { Hal yang harus } \\
\text { dicapai berlandaskan } \\
\text { nilai penting yang } \\
\text { mengacu pada } \\
\text { Undang-Undang } \\
\text { Republik Indonesia } \\
\text { Nomor } 11 \text { Tahun } \\
2010 \text { tentang Cagar } \\
\text { Budaya. }\end{array}$ & $\begin{array}{l}\text { Sebuah awal yang baik dalam } \\
\text { penentuan mitigasi } \\
\text { kebencanaan dan memetakan } \\
\text { segala bentuk potensi-potensi } \\
\text { kebencanaan yang akan } \\
\text { mengancam cagar budaya. }\end{array}$ \\
\hline 2. & $\begin{array}{l}\text { Kekuatan dari } \\
\text { rumpun } \\
\text { bangsa } \\
\text { Melayu yang } \\
\text { sangat dekat } \\
\text { dengan religi. }\end{array}$ & $\begin{array}{l}\text { Pembagian } \\
\text { deliniasi } \\
\text { berdasarkan } \\
\text { pada sistem } \\
\text { zonasi. }\end{array}$ & $\begin{array}{l}\text { Sosialisasi dengan } \\
\text { masyarakat melalui } \\
\text { pendekatan } \\
\text { partisipatoris. }\end{array}$ & $\begin{array}{l}\text { Membuat simulasi siaga } \\
\text { bencana pada Masjid Raya } \\
\text { Sultan Riau agar jika sewaktu- } \\
\text { waktu terjadi kebencanaan } \\
\text { segera tanggap dan sigap dalam } \\
\text { melakukan penyelamatan cagar } \\
\text { budaya. }\end{array}$ \\
\hline 3. & $\begin{array}{l}\text { Koordinasi } \\
\text { dengan } \\
\text { pemangku } \\
\text { kepentingan } \\
\text { (stakeholder). }\end{array}$ & $\begin{array}{l}\text { Penentuan skala } \\
\text { prioritas } \\
\text { penyelamatan } \\
\text { Cagar Budaya. }\end{array}$ & $\begin{array}{l}\text { Peningkatan } \\
\text { kerjasama dengan } \\
\text { komunitas lokal baik } \\
\text { itu LSM atau } \\
\text { komunitas pecinta } \\
\text { budaya. }\end{array}$ & $\begin{array}{l}\text { Sosialisasi berkala dengan } \\
\text { melibatkan BNPB, TNI, Polri } \\
\text { dan juga tim ahli dari BPCB } \\
\text { Sumatra Barat. }\end{array}$ \\
\hline 4. & $\begin{array}{l}\text { Sarana } \\
\text { pendukung } \\
\text { untuk wisata } \\
\text { bahari. }\end{array}$ & $\begin{array}{l}\text { Memperba-nyak } \\
\text { tanda-tanda } \\
\text { peringatan di } \\
\text { beberapa titik } \\
\text { rawan potensi } \\
\text { kebencanaan. }\end{array}$ & $\begin{array}{l}\text { Pengembangan } \\
\text { wisata bahari harus } \\
\text { diimbangi dengan } \\
\text { kesadaran masyarakat } \\
\text { akan potensi ancaman } \\
\text { dari laut. }\end{array}$ & $\begin{array}{l}\text { Sosialisasi dari pemangku } \\
\text { kepentingan baik swasta } \\
\text { maupun pemerintah dan TNI- } \\
\text { Polri terkait adanya potensi } \\
\text { ancaman dari laut. }\end{array}$ \\
\hline
\end{tabular}

Sumber: Analisis penulis

\section{Pola Mitigasi Kebencanaan Masjid Raya Sultan Riau}

Zonasi Pulau Penyengat dijadikan sebagai sebuah kawasan tinggalan arkeologis dalam satu zonasi yang bergabung dengan seluruh cagar budaya di pulau tersebut. Zonasi digunakan untuk menjaga keutuhan situs cagar budaya agar berkelanjutan, sehingga diperlukan pembangunan mitigasi kebencanaan di sekitar situs. Diperlukan identifikasi potensi kebencanaan sebagai bentuk kesadaran paling mendasar dalam rangka menghindari kerusakan cagar budaya. Berikut zonasi cagar budaya di Pulau Penyengat (Gambar 2). 


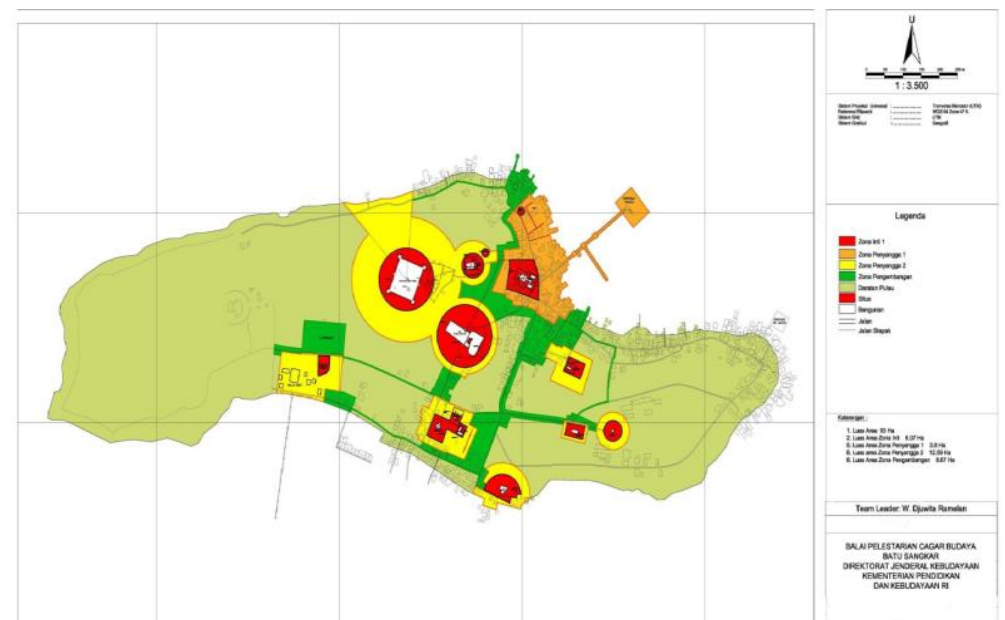

Gambar 2. Peta Zonasi Bangunan Cagar Budaya di Pulau Penyengat (Sumber: Ramelan dkk., 2017).

Identifikasi bencana mengedepankan aspek lingkungan sekitar cagar budaya, seperti pada lokasi Masjid Raya Sultan Riau yang sangat dekat dengan laut dan berpotensi terdampak arus pasang tinggi. Hal ini dapat mengakibatkan rusaknya cagar budaya secara perlahan-lahan akibat terkikis oleh air laut. Selain itu juga kondisi lingkungan masyarakat sangat berpengaruh kuat terhadap ancaman bencana lainnya seperti kebakaran. Hal ini dikarenakan rangkaian kabel listrik yang tidak terpasang rapi maka sewaktu-waktu dapat menjadi potensi ancaman kebakaran dan berakibat langsung pada Masjid Raya Sultan Riau. Dalam mitigasi bencana, masyarakat diharapkan lebih meningkatkan partisipasinya dalam pengelolaan perancangan mitigasi. Adapun dalam menjaga kebersihan dan merawat karena tempat tersebut dibangun untuk jangka panjang serta berkelanjutan. Partisipasi oleh masyarakat diharapkan agar mau bekerja sama lebih giat untuk mencapai tujuan secara efektif (Lakosa dan Alhadi, 2019).

Mitigasi kebencanaan pada tinggalan arkeologis sudah diatur dalam UndangUndang Republik Indonesia Nomor 11 Tahun 2010 tentang Cagar Budaya dalam pasal 58 ayat 1 yang berbunyi: Penyelamatan Cagar Budaya dilakukan untuk: mencegah kerusakan karena faktor manusia dan/atau alam yang mengakibatkan berubahnya keaslian dan nilai-nilai yang menyertainya; dan mencegah pemindahan dan beralihnya kepemilikan dan/atau penguasaan Cagar Budaya yang bertentangan dengan ketentuan peraturan perundang-undangan. Ayat 2 menjelaskan Penyelamatan sebagaimana dimaksud pada ayat 1 dilakukan dalam keadaan darurat dan keadaan biasa. Berdasarkan pada konteks dalam aturan perundang-undangan tersebut maka mitigasi kebencanaan yang dapat dilakukan pada Masjid Raya Sultan Riau dilakukan dengan menetapkan langkah-langkah sebagai berikut:

1. Mengadakan studi kelayakan wilayah dan identifikasi kebencanaan terhadap potensi ancaman kebencanaan Masjid Raya Sultan Riau.

2. Mengintegrasikan dengan zonasi Pulau Penyengat secara keseluruhan. 
3. Menambah sarana dan prasarana penunjang bagi mitigasi kebencanaan seperti alat pemadam kebakaran, dan jalur evakuasi menuju titik aman.

4. Penentuan skala prioritas penyelamatan cagar budaya.

5. Sosialisasi berkala dengan melibatkan BNPB, TNI, Polri dan juga tim ahli dari BPCB Sumatra Barat.

6. Peningkatan kerjasama dengan komunitas lokal baik itu LSM atau komunitas pecinta budaya.

7. Membuat simulasi siaga bencana pada Masjid Raya Sultan Riau agar jika sewaktuwaktu terjadi kebencanaan segera tanggap dan sigap dalam melakukan penyelamatan cagar budaya.

8. Memperbanyak tanda-tanda peringatan di beberapa titik rawan potensi kebencanaan.

\section{SIMPULAN}

Masjid Raya Sultan Riau berada pada Pulau Penyengat yang merupakan salah satu destinasi pariwisata di Provinsi Kepulauan Riau. Bangunan cagar budaya ini masih digunakan oleh masyarakat setempat sehari-hari untuk melakukan kegiatan keagamaan seperti salat. Letak masjid yang tidak jauh dari bibir pantai menjadikan Masjid Raya Sultan Riau berpotensi rusak akibat bencana alam terutama ombak pasang yang tinggi. Adapun dari hasil analisis SWOT menjelaskan mengenai nilai penting dari Masjid Raya Sultan Riau. Dari nilai penting tersebut dapat memberikan gambaran tentang kondisi Masjid Raya Sultan Riau yang masih dipergunakan untuk berbagai keperluan dari masa kesultanan Riau-Lingga sampai sekarang.

Strategi SO dapat dilakukan dengan mengkoordinasikan pihak yang berkepentingan untuk saling mendorong dan memaksimalkan potensi Masjid Raya Sultan Riau melaui rapat terpumpun, seminar, wawancara tokoh setempat, dan lain sebagainya. Strategi WO dapat digunakan sebagai bahan evaluasi dalam pengembangan berdasarkan pada zonasi seperti pembagian deliniasi serta penentuan skala prioritas penyelamatan cagar budaya serta memperbanyak tanda-tanda peringatan di beberapa titik rawan yang berpotensi terjadinya bencana. Strategi ST merupakan hal yang harus dicapai yang dilandaskan pada nilai penting dan rasa memiliki dari masyarakat serta komunikasi antara pemangku kepentingan seperti LSM atau komunitas pecinta budaya. Strategi WT melakukan penentuan mitigasi kebencanaan, memetakan, dan melaksanakan simulasi segala bentuk potensi kebencanaan yang akan mengancam keberlangsungan Masjid Raya Sultan Riau.

Mitigasi bencana pada Masjid Raya Sultan Riau diharapkan dapat menjadi salah satu hal utama yang dapat dilakukan mengingat letak masjid yang dekat dengan pantai. Kondisi ini sangat mengkhawatirkan jika tidak segera ditindak lanjuti dengan membuat mitigasi kebencanaan. Dalam pelestarian cagar budaya mitigasi kebencanaan berperan untuk menjaga nilai penting baik fisik maupun non fisik. Sedangkan secara khusus mitigasi kebencanaan memiliki tujuan untuk meminimalisasikan dampak kerusakan akibat bencana yang terjadi, sebagai landasan bagi pengembangan dan pemanfaatan 
cagar budaya, serta meningkatkan kesadaran masyarakat terhadap pentingnya menjaga cagar budaya agar tetap lestari.

\section{DAFTAR PUSTAKA}

Chandra, Dodi. 2018. "Mitigasi Bencana dalam Konteks Pelestarian Cagar Budaya." Diunduh 17 November 2020.

(http://kebudayaan.kemdikbud.go.id/bpcbsumbar/mitigasi-bencana-dalam-kontekspelestarian-cagar-budaya/)

Firdaus, Muhammad, Yales Veva Jaya, dan Dony Apdillah. 2013. “Aplikasi SIG untuk Penentuan Daerah Potensial Rawan Bencana Pesisir di Kota Tanjungpinang Provinsi Kepulauan Riau." Jurnal Umrah: 1-8.

Indonesia, Kementerian Pendidikan dan Kebudayaan Republik. 2010. Undang-Undang Republik Indonesia Nomor 11 Tahun 2010 tentang Cagar Budaya. Indonesia.

Junus, Hasan. 2002. Engku Puteri Raja Hamidah Pemegang Regalia Kerajaan Riau. Tanjungpinang: Unri Press.

Lakosa, Fegi Yani, dan Zikri Alhadi. 2019. "Analisis SWOT dalam Pelaksanaan Pengelolaan Tempat Evakuasi Sementara oleh BPBD Kota Padang." JESS (Journal of Education on Social Science) 3(2): 57-66.

Menteri Kebudayaan dan Pariwisata. 2003. Surat Keputusan Menteri Kebudayaan dan Pariwisata Nomor KM.9/PW.007/MKPO3 Tentang Penetapan Kompleks Percandian Muara Takus, Balai Kerapatan Tinggi Siak, Istana Siak Sri Indrapura, Istana Raha Ali Marhum Kantor, Raja Ali Marhum Kantor, Makam Raja Abdurrah. Indonesia. Dunduh 25 Juni 2021

(http://kebudayaan.kemdikbud.go.id/bpcbsumbar/wpcontent/uploads/sites/28/2019/ 11/2003Kepmenbudpar_KM.9.PW_.007.MKP_.2003.pdf).

Olisstiowati, Cifta Ayu, Bedriati Ibrahim, dan Tugiman. 2019. "Sejarah Masjid Raya Sultan Riau di Pulau Penyengat Kota Tanjung Pinang Provinsi Kepulauan Riau." Jurnal Online Mahasiswa Fakultas Keguruan dan Ilmua Pendidikan Universitas Riau 6(1): 1-11.

Pratikno, Hendro, Hayatul Khairul Rahmat, dan Siswo Hadi Sumantri. 2020. "Implementasi Cultural Resource Management dalam Mitigasi Bencana pada Cagar Budaya Di Indonesia." Nusantara: Jurnal Ilmu Pengetahuan Sosial 7(2): 427-36.

Ramelan, W. Djuwita Sudjana et al. 2015. "Model Pemanfaatan Kawasan Cagar Budya Trowulan Berbasis Masyarakat." Amerta 33(1): 63-76.

Rangkuti, Freddy. 2011. SWOT Balanced Scorecard: Teknik Menyusun Strategi Korporat yang Efektif Plus Cara Mengelola Kinerja dan Resiko. Jakarta: PT Gramedia Pustaka Utama.

Tanudirjo, Daud Aris. 2004. "Penetapan Nilai Penting dalam Pengelolaan Benda Cagar Budaya." dalam Rapat Penyusunan Standardisasi Kritetia (Pembobotan) Bangunan Benda Cagar Budaya, di Rumah Joglo Rempoa, Ciputat, Jakarta, 26--28 Mei 2004. Tidak diterbitkan.

Trisoko, Riono Gede. 2015. "Promosi Mesjid Raya Pulau Penyengat sebagai Daerah Tujuan Wisata di Tanjung Pinang Kepulauan Riau.” Jurnal Daya Saing 1(3): 28195.

Zulfiar, M. Heri, Tamin, Krishna S. Pribadi, dan Iswandi Irwan. 2014. "Identifikasi Faktor Dominan Penyebab Kerentanan Bangunan Di Daerah Rawan Gempa, Provinsi Sumatera Barat.” Semesta Teknika 17(2): 116-25. Diunduh 17 November 
2020 (https://journal.umy.ac.id/index.php/st/article/view/419).

HASIL DISKUSI

Tidak ada pertanyaan 